\title{
THE VALUE OF \\ GALACTOSE PHOSPHATE DETERMINATIONS IN THE TREATMENT OF GALACTOSAEMIA
}

\author{
BY \\ V. SCHWARZ \\ From the Departments of Child Health and Pathology, University of Manchester
}

(RECEIVED FOR PUBLICATION JULY 29, 1960)

Hereditary galactosaemia is now known to be due to the deficiency of a single enzyme, galactose-1phosphate uridyl transferase* (Kalckar, Anderson and Isselbacher, 1956). This enzyme, the second in the chain of three enzymes concerned with the metabolism of galactose, catalyses the conversion of gal-1-P to G-1-P, as shown in equation (2):

$$
\begin{aligned}
\text { gal }+ \text { ATP } & \rightarrow \text { gal-1-P }+ \text { ADP } \\
\text { gal-1-P }+ \text { UDPG } & \rightleftharpoons \text { G-1-P + UDPgal } \\
\text { UDPgal } & \rightleftharpoons \text { UDPG }
\end{aligned}
$$

The block in galactose metabolism at step (2) would be expected to lead to an accumulation of gal-1-P when galactosaemic individuals ingest galactose. An accumulation of this phosphate has been demonstrated in the erythrocytes of untreated infants suffering from galactosaemia, or in the erythrocytes of treated cases after incubation with galactose in vitro (Schwarz, Golberg, Komrower and Holzel, 1956; Kalckar et al., 1956). A diagnostic test for galactosaemia, based on this observation, has been reported previously (Schwarz, Holzel and Komrower, 1958).

The intracellular accumulation of gal-1-P appears to lead to a serious disturbance of erythrocyte metabolism, as indicated by a fall in the respiratory rate and by a general derangement of phosphate metabolism (Schwarz et al., 1956; Komrower, Schwarz, Holzel and Golberg, 1956; Penington and Prankerd, 1958). An analogous disturbance has been demonstrated in a mutant of $E$. coli deficient in uridyltransferase: on incubation of the culture with galactose, it evinces a prolonged lag phase before the onset of growth, which is preceded by intracellular accumulation of gal-1-P (Kurahashi

\footnotetext{
* The following abbreviations will be used: Galactose-1-Phosphate, gal-1-P; Glucose-1-phosphate, G-1-P; adenosine triphosphate and diphosphate, ATP and ADP; uridinediphosphoglucose or - galactose UDPG and UDPgal.
}

and Wahba, 1958). Recently evidence has been presented which indicates that gal-1-P may exert an inhibitory effect on a number of enzymes-phosphoglucomutase, G-6-P phosphatase and dehydrogenase (Sidbury, 1957; Ginsburg and Neufeld, 1957; Lerman, 1960).

So far gal-1-P has been demonstrated only in the erythrocytes of galactosaemic infants. The liver, being the main site at which galactose is normally metabolized, would be expected to show a similar, or even greater, accumulation of this phosphate. Theoretically, all cells of the body are endowed, to a greater or lesser extent, with all enzymes and a hereditary deficiency in one enzyme might therefore make itself felt in all tissues.

The purpose of this communication is threefold: to demonstrate that gal-1-P does, in fact, accumulate in several, if not all, tissues; to draw attention to the value of assessing erythrocyte gal-1-P at regular intervals as a guide to the adequacy of treatment; to present an improved method for the determination of gal-1-P.

The gal-1-P values reported below were obtained by the method published previously (Schwarz et al., 1958). Since this method was evolved and most of the determinations made, pure gal-1-P has become available, thus permitting an assessment of the efficiency of its determination. Recent experiments have shown that the original method may involve losses of galactose resulting from irreversible adsorption on, or entrainment in, the salts left after evaporation to dryness. To overcome this defect as far as possible, and still retain the specificity of the method accruing from chromatographic separation of galactose from other carbohydrate or reducing substances, the following method has been devised.

\section{Determination of Gal-1-P}

Heparinized venous blood (about $2 \mathrm{ml}$.) which may be kept in ice (not frozen) for a few hours, is centrifuged 
in a conical graduated tube to separate the cells. After washing the cells with three changes of $10 \mathrm{ml}$. saline, the cell volume is noted.

The cells are lysed by shaking with two volumes of water and a little saponin, and by freezing. To the partially thawed haemolysate three cell volumes of icecold $20 \%$ trichloracetic acid are added: the mixture is shaken well and kept exactly six minutes in an ice bath, with occasional shaking; it is centrifuged for two minutes in ice-cold buckets and the supernatant is immediately poured through a sintered glass filter.

The filtrate, whose volume is measured, is transferred to a $15 \mathrm{~cm}$. glass stoppered tube, containing three drops of $25 \%$ barium acetate, one drop of phenolphthalein solution and $5 \mathrm{ml}$. ethanol, previously cooled in ice. A slight excess of $40 \% \mathrm{KOH}$ is added. It is important to carry out these operations quickly and to keep the mixture cold while the $p \mathrm{H}$ is acid, since the gal-1-P is easily hydrolysed in acid solution. The ice-cold mixture is acidified with the minimum amount of acid and then basified to a faint pink with $0 \cdot 1 \mathrm{~N} \mathrm{KOH}$. This solution is treated with four volumes of ethanol, re-neutralized if necessary, and kept in the refrigerator for at least two hours (or over night).

The precipitated barium phosphates are spun down and the supernatant is rejected.

Ice-cold neutralized $80 \%$ ethanol $(10 \mathrm{ml}$.) is added and the precipitate is suspended by swirling the tube and then allowed to settle in the refrigerator for one hour. After centrifugation the supernatant is again rejected.

The residue is treated with $1.5 \mathrm{ml} .0 \cdot 1 \mathrm{~N} \mathrm{HCl}$ and the mixture is immersed in boiling water and shaken to disperse the precipitate. The tube is stoppered (spring loaded) and immersed in boiling water for 15 minutes.

After cooling, the tube is centrifuged briefly and the hydrolysate is de-ionized as follows: it is transferred to a tube $(10 \times 1.5 \mathrm{~cm}$. $)$ containing $0.2 \mathrm{~g}$. of Amberlite Monobed resin MB-1 (analytical grade), previously washed with several changes of boiled distilled water. The mixture is shaken mechanically for 15 minutes, keeping the resin as far as possible near the bottom of the tube. After a brief centrifugation the solution is transferred with a fine-tipped Pasteur pipette, reaching to the bottom of the tube, to a $5 \mathrm{ml}$. volumetric flask. The boiling tube is rinsed three times with $1 \mathrm{ml}$. of water, the separate rinsings being used to extract the resin for five minutes each time. The solution is transferred to the flask and the volume is finally made up to the mark.

Two aliquots of $2 \mathrm{ml}$. are transferred to evaporating cups, made by cutting off test tubes of $1 \cdot 3 \mathrm{~cm}$. diameter about $2.5 \mathrm{~cm}$. from the bottom. The solutions are evaporated to dryness in a vacuum desiccator.

One of the cups is rinsed round with five or six portions of $50 \%$ methanol to dissolve the galactose and transfer it quantitatively to the starting line of a descending chromatogram. This is run on a sheet of no. 1 Whatman paper, $58 \mathrm{~cm}$. long, with a $10 \mathrm{~cm}$. long folded strip of paper stapled to the bottom. Known amounts of galactose (5-50 $\mu \mathrm{g}$.) are placed alongside the sample. After 30 minutes' equilibration the chromatogram is run for
16 to 20 hours in ethyl acetate-pyridine-water (70:25:20 by vol.) at $27^{\circ} \mathrm{C}$.

After drying at room temperature, the chromatogram is dipped in freshly prepared benzidine reagent $(0.5 \mathrm{~g}$. of decolorized benzidine in $5 \mathrm{ml}$. glacial acetic acid and $20 \mathrm{ml}$. acetone, to which $4 \mathrm{ml} .100 \%$ trichloracetic acid and acetone to $100 \mathrm{ml}$. is added) (Harris and MacWilliam, 1954). The chromatogram is heated for two to four minutes in an oven at $100^{\circ} \mathrm{C}$. until the paper begins to turn pale yellow.

The amount of galactose in the aliquot used for chromatography is estimated visually by comparison with known amounts, either in daylight or in ultraviolet light, taking into account both the yellow colour (daylight) or greenish yellow fluorescence (u.v.) given by $0 \cdot 2-10 \mu \mathrm{g}$. quantities of galactose, and the brown centres (non-fluorescent) given by larger amounts. The other aliquot of the de-ionized dried hydrolysate is available, if necessary, for making a closer assessment of the galactose content on the basis of the first result.

Results Obtained by the Improved Method. In four experiments in which pure gal-1-P had been added to a normal haemolysate and glucose-1-C $\mathrm{C}^{14}$ to the hydrolysate, the recoveries were as shown in Table 1 . It can be seen from this Table that about $90 \%$ of the labelled glucose has been recovered. The loss of about $10 \%$ of the glucose (probably due to irreversible adsorption on the resin) is, presumably, paralleled by a similar loss of galactose. A recovery of $90 \%$ is thus the best of which the method is capable. The maximum error involved in the visual assessment of galactose on the chromatogram is of the order of $10 \%$. The over-all accuracy of this method can be considered adequate for the purpose of routine checks of erythrocyte gal-1-P levels.

TABLE 1

PERCENTAGE RECOVERY OF ADDED GAL-1-P FROM HAEMOLYSATE

\begin{tabular}{c|c|c}
\hline Experiment & Glucose-1-C14 & Gal-1-P \\
\hline 1 & $93 \cdot 1$ & 100 \\
2 & $90 \cdot 2$ & 92 \\
3 & 91.2 & 84 \\
4 & 88.8 & 100 \\
\hline
\end{tabular}

\section{Untreated Cases}

Table 2 shows the gal-1-P levels found in untreated cases, aged 10-28 days, and in a patient of $4 \frac{1}{2}$ months after eight days on a milk diet. (The results reported below were obtained by the original method of Schwarz et al. (1956) as indicated in the introduction and are liable to be somewhat too low.)

With the exception of L.B. (whose clinical record was not available), the values are between 300 and $400 \mu \mathrm{g} . / \mathrm{ml}$., irrespective of age. This suggests that the galactose phosphate level may tend to a maximum attained after prolonged exposure of the cells to galactose. 
TABLE 2

GAL-1-P IN UNTREATED CASES

\begin{tabular}{c|c|c}
\hline Patient & Age & $\begin{array}{c}\text { Gal-1-P } \\
(\mu \mathrm{g} . / \mathrm{ml} . \text { cells })\end{array}$ \\
\hline Susan B. & $1 \frac{1}{2}$ weeks & 360 \\
S.B. & 3 weeks & 330 \\
M.C. & 4 weeks & 300 \\
L.B. & 3 weeks(?) & 130 \\
A.J. & $4 \frac{1}{2}$ months & 400 \\
\hline
\end{tabular}

\section{Effect of Treatment}

Fig. 1 shows the rate of progress of three infants. One of these (B.J.) was diagnosed at three days and was fed no milk from birth. Her cord blood contained $50 \mu \mathrm{g}$. gal-1-P/ml. cells, which must have been formed in utero.

After treatment for varying periods, the level of intracellular gal-1-P presumably depends on the galactose content of the diet. The scatter diagram (Fig. 2) shows the values obtained in 36 determinations on 13 patients and five normals. It can be seen that normal values are substantially less than the lowest found in treated galactosaemic infants.

\section{Gal-1-P in Other Tissues}

Organs from two infants who died from galactosaemia before the diagnosis could be made, were obtained at necropsy. In one case (M.C.) the material did not become available for analysis until several days after necropsy, having been left at room temperature in the meantime. The gal-1-P levels are, therefore, of no more than qualitative significance. The results are shown in Table 3, from which it is clear that gal-1-P might reasonably be expected to accumulate in all tissues of the body.

A biopsy specimen of liver taken at laparotomy from a patient in whom haemolytic disease of the newborn as well as other complicating factors were present in addition to galactosaemia, contained $50 \mu \mathrm{g}$. gal-1-P/g. after four months of treatment. The galactose phosphate level in the erythrocytes

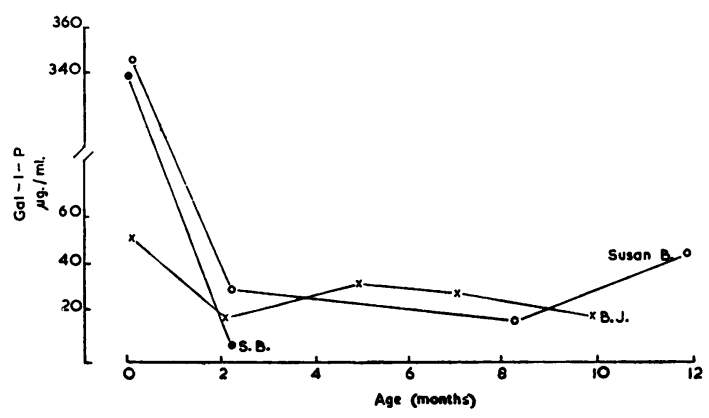

FIG. 1.-Change in gal-1-P levels during treatment.

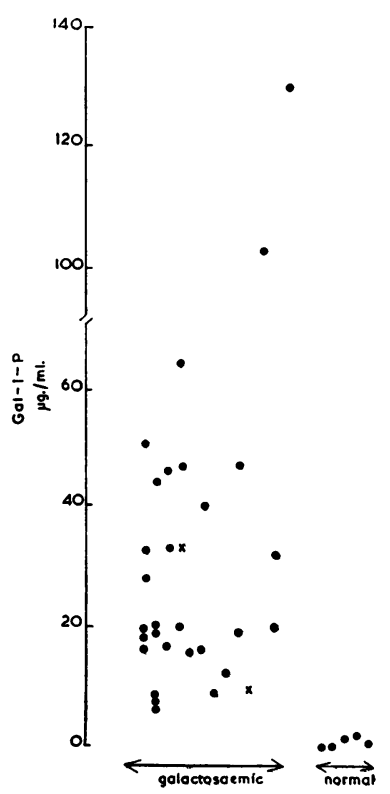

FIG. 2.-Erythrocyte gal-1-P in treated patients. $\quad \times$ indicates blood analysed shortly after exchange transfusion, hence low gal-1-P levels do not reflect adequate treatment.

TABLE 3

GAL-1-P IN ORGANS

\begin{tabular}{l|c|c}
\hline \multicolumn{1}{c|}{ Organ } & $\begin{array}{c}\text { Patient M.C. } \\
(\mu . g . / g .)\end{array}$ & $\begin{array}{c}\text { Patient L.C. } \\
(\mu \mathrm{g} . / \mathrm{g} .)\end{array}$ \\
\hline Whole blood & - & 270 \\
Liver & 20 & $90,75^{*}$ \\
Kidney & 3 & 145 \\
Brain & 0 & $65,69 *$ \\
Tongue & - & - \\
Adrenal & 4 & - \\
Heart & 20 & - \\
\hline Gallstones & 22 & \\
\hline
\end{tabular}

was estimated at the same time and found to be $64 \mu \mathrm{g} . / \mathrm{ml}$.

\section{Discussion}

There is now considerable evidence that gal-1-P, by interfering with the normal metabolism of the cell, may be responsible for the clinical manifestations of galactosaemia. The demonstration that the phosphate accumulates in a variety of tissues of the galactosaemic infant if his diet contains galactose, is in line with the diversity of the symptoms. Even if all tissues are liable to suffer damage from the accumulation of the 'toxic' phosphate, in some the existence of sufficient functional reserve would prevent this damage from manifesting itself clinically.

It may be mentioned here that Schwarz and Golberg (1955) showed that the lens capsules and epithelia of rats suffering from galactose cataract 
contained approximately $170 \mu \mathrm{g}$. gal-1-P/g., whereas non-cataractous lenses of galactose-fed animals contained not more than $0 \cdot 1$ of this amount. Recently, Lerman (1960) has shown that an inhibition of lenticular G-6-P dehydrogenase and of glucose catabolism is demonstrable two to four days after instituting a high galactose diet, and that the ATP content of the tissues drops to very low levels. This interference with normal metabolism might well result from the accumulation of gal-1-P and probably accounts for the gradual opacification.

If one accepts the premise of the 'toxic' nature of galactose phosphate, the question arises at what concentration this substance begins to exert its deleterious effect on cellular metabolism. Unfortunately, it is not yet possible to offer an answer, since it is difficult to simulate intracellular conditions in vitro. In erythrocytes a gal-1-P concentration of $150 \mu \mathrm{g} . / \mathrm{ml}$. was found to inhibit cellular respiration by $30 \%$ (Schwarz et al., 1956), but other, metabolically more active, cells might be more or less affected by such levels. It was pointed out, in connexion with Table 2, that in untreated cases the galactose phosphate concentration rises to what appears to be a maximum of $300-400 \mu \mathrm{g} . / \mathrm{ml}$. Since this level would be reached quite rapidly (12-16 hours, in the presence of sufficient galactose to saturate the enzyme) (Kalckar et al., 1956), it seems that the accumulation of the phosphate is selflimiting, i.e. analogous to the well-known product inhibition of hexokinase.

Since it is not known what constitutes a 'safe' level of intracellular galactose phosphate and since both its rate of formation and its rate of removal may be different in each tissue, the determination of galactose phosphate in erythrocytes can probably furnish no more than an indication of whether the general tissue level is rising or falling. On the single occasion when a biopsy specimen of liver could be examined, the galactose phosphate level was close to that in the erythrocytes, but in the necropsy specimens the levels differed considerably.

The presence of a fairly substantial amount of gal-1-P in the cord blood of a galactosaemic infant raises the question of the mother's diet during pregnancy. In the case recorded no galactose could be detected chromatographically (i.e. less than $5 \mathrm{mg}$. \%) in the mother's venous blood on two occasions after the consumption of one pint of milk. From this one may infer that the galactose phosphate had accumulated in the foetal tissues by prolonged exposure to small amounts of galactose transferred across the placenta.

From the results presented in this paper and from clinical findings reported previously (Komrower et al., 1956), it is clear that, ideally, the galactosaemic infant should be provided with a completely galactose-free diet. In practice such treatment is fraught with difficulties due both to the wide distribution of galactose and to the degree of conscientiousness required on the part of the mother. It should be emphasized here that many foods contain galactose in the form of $\alpha$-galactosides (lactose is a $\beta$-galactoside) which may not be hydrolysed to free galactose in the intestinal tract. But until it is known for certain that no galactose is liberated either by the digestive enzymes or by the intestinal flora, foods containing $\alpha$-galactosides should be avoided (Schwarz, Holzel, Stapleton and Goodell, 1959).

In view of the practical difficulties associated with the diet, regular assessment of the gal-1-P level in the erythrocytes constitutes a ready, and indeed the only, means of checking the adequacy of the diet, from the point of view of exclusion of galactose. The disappearance of frank symptoms is probably not a reliable indication that treatment is adequate and successful, especially as the developing nervous system may be more sensitive than other tissues to a slight but persistent interference with normal metabolism.

Final judgment on the effect of ingesting small amounts of galactose and consequent accumulation of the phosphate in the tissues has to be deferred until more information is available on the maximum level which can build up in the cell without interfering with metabolism. It is, however, well to consider that a uniform distribution of gal-1-P in the total intracellular water corresponding to a level of $150 \mu \mathrm{g} . / \mathrm{ml}$. erythrocytes, which is known to affect erythrocyte metabolism, would be equivalent to about $400 \mathrm{mg}$. of galactose for a $7 \mathrm{~kg}$. infant. Since a much lower concentration of the phosphate might turn out to be damaging, it will be appreciated that the amount of galactose involved is quite small. Thus, a 'low lactose' milk, claimed by the manufacturers to contain, in the reconstituted condition, not more than $0.012 \%$ galactose, i.e. equivalent to $400 \mathrm{mg}$. in $3 \frac{1}{2}$ litres., would supply what might be a highly toxic dose in a few days.

It should, however, be emphasized that apart from the gaps in our knowledge of the degree of toxicity of gal-1-P and of the rate of accumulation in different tissues, there is bound to be a considerable variation from one individual to another, due to the variability of such factors as rate of absorption, renal efficiency and, above all, a residual capacity to metabolize galactose by the usual or an alternative pathway (Isselbacher, 1957). In consequence it is impossible to dogmatize on the 
precise significance of particular galactose phosphate levels. Until the gaps in our understanding are closed, a cautious approach is indicated.

\section{Summary}

Hereditary galactosaemia is characterized by a deficiency of the enzyme galactose phosphate uridyltransferase, which catalyses the conversion of galactose-1-phosphate to glucose-1-phosphate. The deficiency leads to an intracellular accumulation of gal-1-P when the patient's diet contains galactose. There is evidence indicating that this phosphate inhibits a number of enzymes and that by these, or other, means it interferes with normal cellular metabolism.

Analysis of necropsy material has shown that galactose phosphate is deposited in several, if not all, tissues, thus probably accounting for the diverse ill-effects constituting the galactosaemic syndrome. The determination of gal-1-P in the erythrocytes affords a ready means of assessing the adequacy of treatment, of which the disappearance of frank symptoms is an insufficient guide. The amounts of galactose potentially capable of damaging cellular metabolism are quite small. This fact and the wide distribution of galactose impose a heavy burden on the galactosaemic patient's mother and clinician alike, thus rendering a regular check by galactose phosphate determination desirable.

An improved method for the estimation of galactose phosphate in erythrocytes is presented.
I would like to thank the many paediatricians who have referred their patients to me and have given their permission to incorporate the results in the scatter diagram. I wish to express my appreciation for the supply of necropsy material by Dr. L. L. R. White and Dr. J. L. Emery. I am indebted to Professor W. Gaisford and Dr. A. H. Gowenlock for valuable discussion. The analyses and much of the development work were carried out by Miss Naomi Simpson, whose skill and patience it is a pleasure to record.

\section{REFERENCES}

Ginsburg, V. and Neufeld, E. (1957). Abstr. Proc. Biol. Chem., Amer. Chem. Soc. September, p. 27c.

Harris G. and MacWilliam, I. C. (1954). A dipping technique for revealing sugars on paper chromatograms. Chem. and Industry, p. 249.

Isselbacher, K. J. (1957). Evidence for an accessory pathway of galactose metabolism in mammalian liver. Science, 126, 652 .

Kalckar, H. M., Braganca, B. and Munch-Petersen, A. (1953). Uridyl transferases and the formation of uridine diphosphogalactose. Nature (Lond.), 172, 1038.

—_, Anderson, E. P. and Isselbacher, K. J. (1956). Galactosemia, a congenital defect in a nucleotide transferase. Biochim. biophys. Acta, 20, 262.

- and Maxwell, E. S. (1958). Biosynthesis and metabolic function of uridine diphosphoglucose in mammalian organisms and its relevance to certain inborn errors. Physiol. Rev., 38, 77.

Komrower, G. M., Schwarz, V., Holzel, A. and Golberg, L. (1956). A clinical and biochemical study of galactosaemia. Arch. Dis. Childh., 31, 254.

Kurahashi, K and Wahba, A. J. (1958). Interference with growth of certain Escherichia Coli mutants by galactose. Biochim. biophys. Acta, 30, 298.

Lerman, S. (1960). Pathogenetic factors in experimental galactose cataract. A.M.A. Arch. Ophthal., 63, 128, 132 and 136.

Penington, J. S. and Prankerd, T. A. J. (1958). Studies of erythrocyte phosphate ester metabolism in galactosaemia. Clin. Sci., 17, 385 .

Schwarz, V. and Golberg, L (1955). Galactose-1-phosphate in galactose cataract. Biochim. biophys. Acta, 18, 310.

, Komrower, G. M. and Holzel, A. (1956). Some disturbances of erythrocyte metabolism in galactosaemia. Biochem. J., 62, 34.

- Holzel, A. and Komrower, G. M. (1958). Laboratory diagnosis of congenital galactosaemia at birth. Lancet, 1, 24.

- Stapleton, T and Goodell, R. A. (1959). Treatment of galactosaemia, Lancet, ii, 1146.

Sidbury, J. B. (1957). Abstr. Proc. Biol. Chem., Amer. Chem. Soc. September. p. 27c. 